\title{
Socio-Cultural Factors that Influence the Adoption of m-Commerce in Nigeria
}

\author{
By Priscilla Omonedo*
}

\begin{abstract}
The rapid uptake of mobile devices globally, has propelled interest in emerging mobile opportunities through which businesses can broaden their customer reach. However, the differing pattern of m-commerce adoption in developed versus developing economies; rapid growth in mobile telephony uptake; and potential for adoption of m-commerce in developing economies, necessitate an understanding of emerging, unique, but less researched factors that can significantly influence the perception, behaviour, acceptance and consequent uptakeladoption of m-commerce within developing economies like Nigeria. Mixed methods of survey (quantitative) and semi-structured interview (qualitative) was employed. Prior to data collection, $n=48$ factors that contribute to successful adoption of $m$-commerce and specific to businesses in developing countries like Nigeria were identified from a rigorous literature review, and placed into four themes: organizational (including managerial), technological, environmental, and consumer factors. Data collection was conducted in two phases. During phase 1, a total of $n=12$ interviews were conducted on owners or managers of micro and small businesses (MSBs) across Nigeria. The interview data was thematically analysed based on three themes - organizational, technological and environmental factors, and further categorised as facilitators and barriers. During phase 2, $n=230$ questionnaires were administered on owners or managers of MSBs across Nigeria to gain further insight into facilitators and barriers identified from Phase 1. Questionnaire reliability and validity was undertaken prior to data collection. Data analysis was conducted on $n=197$ responses (due to incomplete entries), using relative frequency statistics to highlight the significance of the factors based on their level of impact. The socio-cultural factors identified are personal relationship, ostentatious culture, and multi-SIM culture, informed by results that showed that $80.95 \%$ of respondents placed emphasis on physical contact (personal relationship); $88.57 \%$ of respondents keep up with global trend (ostentatious culture); and $81.16 \%$ respondents highlighted the affordability of device technology (multi-SIM culture). This paper discusses these results and further highlights effective strategies that businesses in Nigeria adopt to engage positive factors (facilitators), and address negative factors (barriers) in order to harness the huge potentials that m-commerce uptake provides. Overall, existing businesses and those seeking to operate in cultures similar to the Nigerian context e.g. India, can focus and leverage these factors to significantly facilitate their adoption of m-commerce, and deliver promising benefits to their businesses.
\end{abstract}

Keywords: Socio-cultural factors, m-commerce adoption, mobile phones, developing countries, Nigeria

\section{Introduction}

Advancements in technology has opened up different channels for the conduct of business electronically e.g., e-commerce (Datta 2011), m-commerce (Omonedo and Bocij 2014), s-commerce (Kim and Park 2012), I-commerce (Xu and Gupta 2009). In recent times, the uptake of mobile telephony, particularly in

${ }^{*}$ Teaching Fellow, Aston Business School, Aston University, UK. 
developing countries has increased (ITU 2014). Recent statistics suggest that the uptake of mobile phones continues to grow rapidly with unique mobile users reaching 5.112 billion, which amounts to $67 \%$ global penetration (WeAreSocial 2019). This implies that mobile platforms, especially mobile phones, presents unique opportunities, innovative business models and niche channel for profitable conduct of business through m-commerce. However, despite the observed growth in mobile telephony and access to the internet, there appears to be low levels of $\mathrm{m}$ commerce adoption by businesses in developing countries, warranting the need to identify ways through which businesses can adopt $\mathrm{m}$-commerce. This will require an understanding of factors that influence the adoption of m-commerce.

The aim of this research is to investigate the factors that influence micro and small businesses to adopt m-commerce in developing countries like Nigeria. A range of socio-cultural factors were identified from this research that provides insight into (a) current trends of adoption among the target population, and (b) effective and unique strategies being engaged by micro and small businesses in their adoption of $\mathrm{m}$-commerce. Nigeria was selected as a case study for the paper, because of the emerging market for m-commerce, propelled by increased uptake of mobile telephony. For example, tele-density in Nigeria rose from $29.98 \%$ to 106.64\% between 2007 and 2018 (NCC 2018).

This paper, the third in a series (Omonedo and Bocij 2014, Omonedo and Bocij 2017), discusses three less researched but unique factors across the breadth of identified socio-cultural factors, that businesses within developing economies can either take advantage of (facilitators) or address (barriers), in order to achieve and benefit from m-commerce adoption. The identified socio-cultural factors personal relationship, ostentatious culture and multi-SIM culture were focused on because, despite their uniqueness to, and potential to enhance the adoption of $\mathrm{m}$ commerce in developing economies like Nigeria, they have not been previously captured or are less researched in the literature. It should also be noted that these factors may be observed in cultures that are similar in context to Nigeria and would benefit from the findings of this study.

Added to the factors that influence $m$-commerce adoption in Nigeria, the paper also highlights recommendations and practical steps toward leveraging the factors to enhance m-commerce adoption. The discourse is underpinned by literature, juxtaposed with findings from a survey and interview of micro and small business owners/managers in Nigeria, which provides useful insight into current adoption trends, and effective strategies being engaged by these businesses. This contribution is particularly useful because some of the socio-cultural factors and ongoing strategies have not been captured in previous m-commerce adoption studies on developing countries such as Nigeria. The methodology underpinning the study, its findings, summary and conclusion are also presented in the paper.

\section{Literature Review}

The term m-commerce, also known as mobile commerce, can be defined as "the conduct of activities that involves content delivery (notification and reporting) 
and transactions (purchasing, transfers, data entry) via mobile devices that are capable of gaining access to a network, particularly the internet, and which provides direct or indirect commercial benefit" (Omonedo and Bocij 2014). This implies that $\mathrm{m}$-commerce is largely accessible via mobile devices that have the ability to connect to a network. One of such devices is the mobile phone which is arguably the largest driver of m-commerce adoption today, given its rapid uptake globally, particularly in developing countries (ITU 2017).

Mobile telephony in developed countries offers many unique, innovative channels through which customers engage with businesses and pay for goods and services, although, these benefits are yet to be fully harnessed in developing countries. This is partly because access to the internet is less in developing countries when compared to developed countries (ITU 2017). This challenge however, led to innovative m-commerce activities in developing countries, such as funds transfer, through the use of airtime recharge or top-up. This involves a sender buying airtime - mobile phone recharge card(s) or top up voucher - worth the amount to be transferred; sending the PIN of the recharge card or top up voucher to the fund recipient, who in turn sells or exchanges the PIN for cash. This innovation has not been previously captured in existing $\mathrm{m}$-commerce literature, despite aligning to Omonedo and Bocij (2014)'s definition of m-commerce. Other $\mathrm{m}$-commerce service innovation in developing economies include mi-Life for buying insurance products in Ghana; Kilimo Salama for protecting farmers in Kenya; m-Pesa for mobile money transfer across Africa.

Over the years, theories have aided the understanding of aspects of $\mathrm{m}$ commerce adoption, particularly with regards to factors that influence (facilitate) its adoption. In literature, three major theories have been used to understand patterns of adoption within information technology (Khalifa and Shen 2008). These three theories - Innovation Diffusion Theory (IDT), Technology Acceptance Model (TAM) and Theory of Planned Behaviour (TPB) - have also been used, modified or adapted to understand m-commerce adoption, particularly from consumers' perspective. Al-Jabri and Sohail (2012) made use of the Innovation Diffusion Theory to identify factors or attributes that may facilitate or inhibit mobile banking adoption by adult banking users in Saudi Arabia. Other studies have used the Technology Acceptance Model to identify or establish factors that influence m-commerce adoption in different contexts. However, Technology Acceptance Model does not capture subjective norms such as trust, in understanding the factors that affect technology adoption. This underscores why most studies favour a combination of models, such as Luarn and Lin (2005) that combined constructs from TAM and TPB, and Wu and Wang (2005) that used TAM and IDT to inform their study. Going further, factors identified from the literature as affecting e-commerce adoption, which may be categorized into four broad components: managerial, organizational, technological and environmental factors (Molla and Licker 2005), can foster understanding of factors influencing $\mathrm{m}$-commerce adoption within organisations.

Majority of existing m-commerce studies have focused on different aspects of m-commerce adoption, with only a limited number focusing on m-commerce adoption within developing countries. Different factors have been suggested to 
influence the adoption of m-commerce and they include: usability (Min et al. 2009); perceived cost (Wei et al. 2009); perceived usefulness (Khalifa and Shen 2008); customer loyalty (Benou et al. 2012); social influence (Omonedo and Bocij 2017); design aesthetics (Cyr et al. 2006); access issues (Bouwman et al. 2007); trust (Wei et al. 2009); privacy (Khalifa and Shen 2008); policy and management irregularities (Song 2010); limited processing power (Lee and Benbasat 2003); perceived enjoyment (Nysveen et al. 2005); lack of security (Zhang et al. 2002); personal innovativeness ( $\mathrm{Lu}$ et al. 2005); and limited input/output interface (Lee and Benbasat 2003).

Authors across different countries have identified various socio-cultural factors that influence m-commerce adoption and they include trust (Efendioglu et al. 2005), social influence (Wei et al. 2009), word of mouth (Hajli et al. 2014), et cetera (Figure 1). The socio-cultural factors have been researched to varying degrees. Zhang et al. (2012) found that culture has moderating effect on the adoption of $\mathrm{m}$-commerce, which may explain discrepancies in adoption trends. For example, Xin (2009) revealed that the unique Japanese culture was amongst other factors that contributed to the tremendous success recorded by NTT DoCoMo and the iMode; adding that the success of the latter is unique and cannot be replicated. This corroborates the point that unique socio-cultural factors can influence the adoption of technologies like m-commerce within different regions. Therefore, it is important for businesses to be aware of region-specific factors in order to leverage the positives or adopt strategies to mitigate the impact of negatives. This paper will zoom in on three socio-cultural factors that are less researched and unique to cultures similar to Nigeria (Figure 1).

Figure 1. Examples of Socio-Cultural Factors that can Influence m-Commerce Adoption in Different Economies

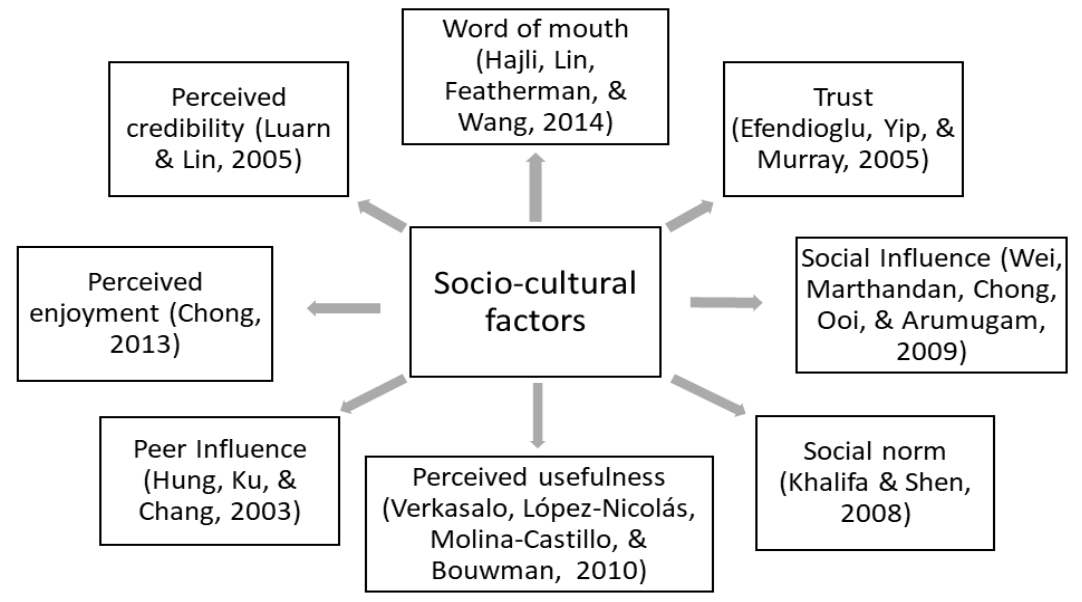

\section{Methodology}

This study was conducted using a mixed methods approach - Surveys (Quantitative method) and Semi-structured Interviews (Qualitative method). Prior to data collection, factors that generally contribute towards successful adoption of 
m-commerce were identified through a thorough review of literature. Factors that are specific to businesses in developing countries like Nigeria were also identified. A total of $n=48$ factors were identified from literature and placed into four themes, aligning with themes highlighted by Molla and Licker (2005)'s classification of ecommerce adoption factors - managerial factors, organizational factors, technological factors and environmental factors. However, Molla and Licker (2005)'s four classifications was updated to integrate factors from m-commerce adoption studies focusing on consumers' perspective. Therefore, m-commerce adoption factors from the literature were re-categorised under these four themes organizational factors (which includes managerial factors), technological factors, environmental factors and consumer factors.

Given that the pattern of advancements in technological adoption in developing countries is rapidly changing, and that the reliability of m-commerce adoption factors identified from literature as a true representation of on-going trends could not be guaranteed, primary data was collected using semi-structured interviews and questionnaires from the target population to address potential discrepancies between literature and reality. This was achieved in two phases.

During the first phase of data collection, a total of $n=12$ interviews were conducted with owners or managers of micro and small businesses from at least one state in each of the six geo-political regions of Nigeria. Respondents were recruited by soliciting participants from a list of registered businesses provided by the Nigerian Bureau of Statistics. Also, personal contacts, as well as snowball approach was engaged in recruiting participants for the study. The data collected through interviews were analysed using thematic analysis which helped to capture new trends in the target population. Thematic analysis was conducted using the process recommended by Silverman (2011) and Braun and Clarke (2006) which broadly involves familiarity with the dataset, generating initial codes, searching for themes, reviewing themes, refining themes and producing the report. Factors identified from the semi-structured interviews could potentially be categorised into the aforementioned four themes established from m-commerce literature. However, because data from the interviews was collected with the aim of identifying factors that influence m-commerce adoption from a business perspective, the consumer category (theme) was dropped, resulting in a reduction to three themes - organizational factors, technological factors and environmental factors. At the end of the data analysis for the first phase, identified factors were categorised as facilitators and barriers respectively, and thereafter integrated into the second phase - survey.

For the second phase of data collection, the survey was conducted on a wider sample of owners or managers of micro and small businesses in the six geopolitical regions of Nigeria. This was achieved through the use of questionnaires aimed at providing further insight into the factors identified as facilitators and barriers, whether they are widely reflective and applicable to the target population, and if new factors may be identified. Reliability and validity of the questionnaire was undertaken prior to data collection. A total of $n=230$ questionnaires were administered. However, data analysis was conducted on $n=197$ responses because some responses had incomplete entries. The data was analysed using relative 
frequency statistics to highlight the significance of the factors based on their level of impact.

\section{Results}

Table 1 of the study data showed that micro and small businesses use mobile phones for business activities that includes: calls (95\%); product enquiry (78\%); product reservation $(66 \%)$; which reflects a heavy dependence on mobile phones in Nigeria (Figure 2).

Table 1. Mobile Phone Enabled Business Activity in a Developing Economy

\begin{tabular}{|l|c|c|}
\hline \multicolumn{1}{|c|}{ Activity } & \multicolumn{2}{c|}{ Response } \\
\hline Make business related calls or send text messages & No. & Percent \\
\hline Advertise products via phone call or text message & 188 & 95.43 \\
\hline Make enquiries on products via phone call or text message & 113 & 57.36 \\
\hline Confirm payment via phone call or text message & 154 & 78.17 \\
\hline Receive calls or text messages about product reservation & 128 & 64.97 \\
\hline Sell PIN / numbers e.g., phone recharge, exam registration & 130 & 65.99 \\
\hline & 27 & 13.71 \\
\hline
\end{tabular}

Figure 2. Mobile Phone Enabled Business Activity in a Developing Economy

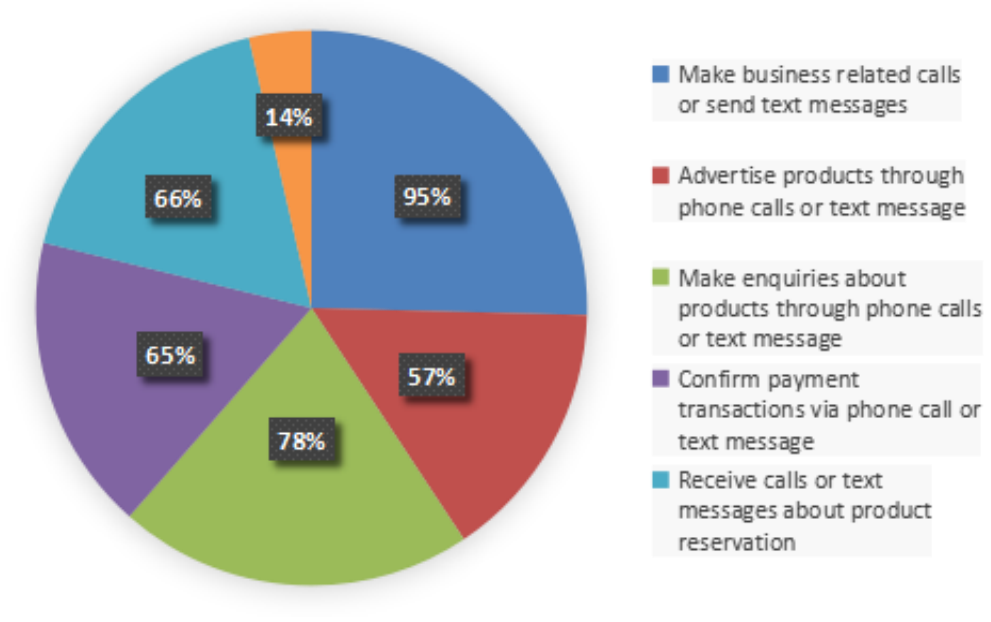

\section{Phase 1}

A total of $n=44$ factors were identified from the interviews. During analysis, it was observed that the data is best understood and interpreted within two broad groupings or themes - facilitators (positive factors) and barriers (negative factors) - irrespective of whether they are organizational, technological or environmental factors. Additionally, the factor grouping was adopted because they make data analysis for the first phase (qualitative), as well as data collection and analysis for the second phase (quantitative) more manageable, which will assist clarity of 
results and discussions. At the end of the data analysis for the first phase, $\mathrm{n}=34$ and $\mathrm{n}=10$ factors were categorised as facilitators and barriers respectively.

\section{Phase 2}

At the end of the data analysis for phase 2, a total of $n=22$ factors were identified that are widely reflective and applicable to the target population. Overall, a total of $n=13$ and $n=9$ factors were returned as facilitators and barriers respectively. Out of the $n=22$ factors identified, $n=4$ factors that includes perceived security, trust, cost and social influence have been previously published (Omonedo and Bocij 2017). For this paper, $n=3$ facilitators and barriers of (a) keep up with Global Trend (ostentatious culture); (b) affordable device technology (multi-SIM culture); and (c) emphasis on physical contact (personal relationship) are presented and discussed (Table 2). The analysis reflects on-going or emerging factors that influence $\mathrm{m}$-commerce adoption by micro and small businesses in Nigeria (Figure $3)$.

Table 2. Sociocultural Factors that Influence m-Commerce Adoption in a Developing Economy

\begin{tabular}{|l|c|}
\hline \multicolumn{1}{|c|}{ Factors } & Response (\%) \\
\hline Keep up with global trend (Ostentatious Culture) & 88.57 \\
\hline Affordable device technology (support Multi-SIM Culture) & 81.16 \\
\hline Emphasis on physical contact (Personal Relationship) & 80.95 \\
\hline
\end{tabular}

Figure 3. Socio-Cultural Factors that Influence m-Commerce Adoption in a Developing Economy

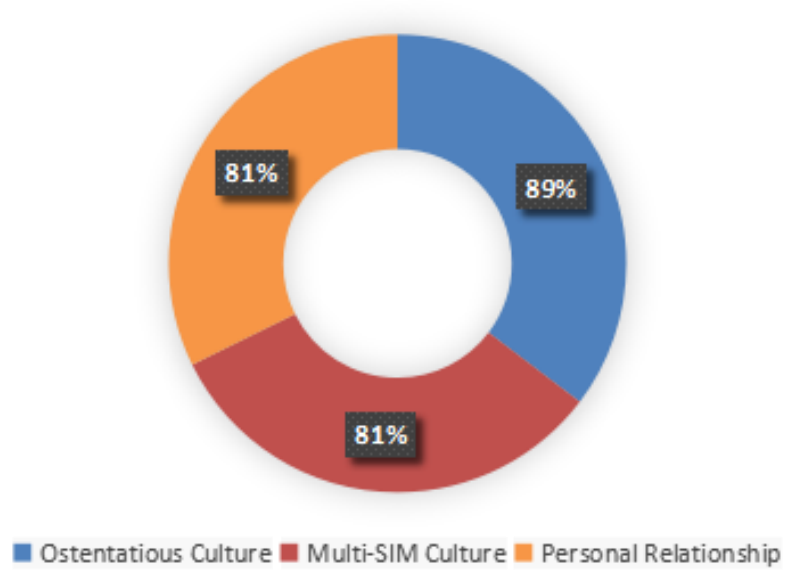

\section{Discussion}

The three socio-cultural factors identified: personal relationship, ostentatious culture, and multi-SIM culture, will be discussed with additional highlight on the strategies businesses in Nigeria adopt in order to engage positive factors 
(facilitators), and address negative factors (barriers) so as to harness the benefits that m-commerce uptake provides (Figure 4).

Figure 4. Socio-Cultural Factors that Influence m-Commerce Adoption in a Developing Economy

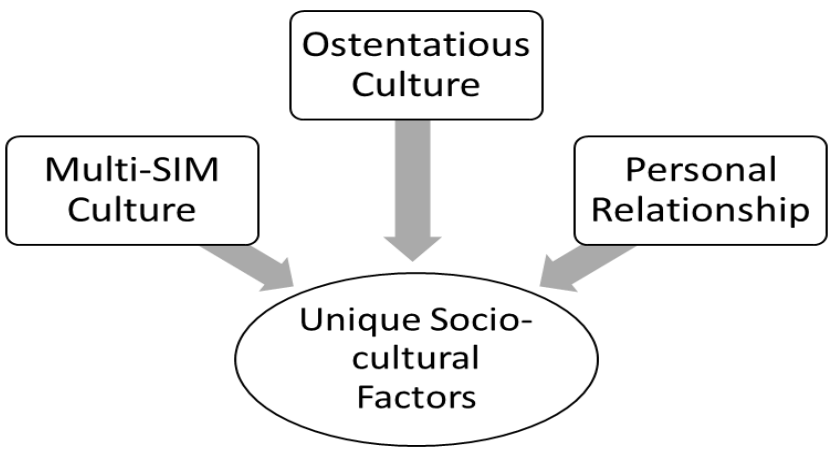

\section{Personal Relationship}

In developing countries like Nigeria, developing good personal relationships with customers is crucial to establishing trustworthy business connections. This is because customers prefer physical or less virtual means to develop relationships with businesses. In some cases, personal relationship for customers in this context akin to physical relationship or physical contact. This features as one of the sociocultural factors that needs to be addressed when considering the conduct of business activities in Nigeria. From the study data, $81 \%$ of micro and small businesses indicated that their adoption of $\mathrm{m}$-commerce was being negatively impacted by personal relationship because customers prefer to make physical contact with the business rather than through the website. This is in line with findings from previous studies on developing countries.

Lawrence and Tar (2010) suggested that in developing countries, "trust is established and reinforced through family association, repeated personal contact and interaction". Hence, the more familiar and aware consumers are with a business and/or its products, the more likely they are to engage in various activities with the business. This is because trust is developed through such familiarity or awareness, which will in turn, influence their decision to engage with the business through non-physical channels such as m-commerce. This reflects Chiemeke and Evwiekpaefe (2011)'s position that the presence of personal trust in a given technology, particularly with regards to security will significantly affect consumers' adoption of such technology.

Practically speaking, consumers in developed countries are not necessarily afraid to buy goods from distant countries. For instance, consumers in UK order items from suppliers in China without entertaining anxiety about whether they will receive the product. In contrast, developing countries have a different culture which places premium on personal, physical contacts and relationships when transacting business. This culture was reaffirmed during the process of collecting data for this study. It was observed that most of the respondents asked lots of 
personal questions about the researcher before granting the interview. Perhaps, these questions were asked as a way of gaining assurance about the genuineness of the author and the research, while at the same time, building trust and confidence in the process. As such, foreign investors into the Nigerian market, as well as local players need to take personal relationship and physical contact into consideration, when seeking to promote consumer trust and confidence in their business and brand. This is even more important when seeking to encourage customer engagement through less physical means like m-commerce.

One useful strategy to adopt in order to win or promote consumer trust is to organise physical campaigns that complement media advertisements. This can provide a platform for consumers to physically interact with the business and ask questions where necessary. While it might be impossible for such campaigns to reach every potential customer, the physical contact can help create a positive buzz in the communities where the campaigns are held and spread positive word about the business, especially through local influencers or significant others, thus creating customer trust in the business.

Although e-commerce research has shown that social word of mouth can positively influence consumer trust (Hajli et al. 2014), a study conducted by Meuter et al. (2013) revealed that interpersonal word of mouth was found to be more influential than various forms of electronic word of mouth. This implies that businesses will potentially benefit from interpersonal word of mouth through physical campaigns compared to electronic campaigns. Once trust is established, the consumers' perception of the business is likely to be positive. It is noteworthy that businesses may not have the capacity to enforce change in customers' perception about factors such as cost, usefulness and enjoyment; but they can provide appropriate information that will help eliminate or minimise wrong notions about them or their product(s). This can contribute towards increasing consumer trust, and by extension, loyalty to the brand. Ball et al. (2004) concluded that though trust may not have direct impact on loyalty, communication had an unexpected impact on loyalty. The implication of the study is that businesses need to leverage customer contact points.

\section{Ostentatious Culture}

Another socio-cultural factor worth considering is the ostentatious culture inherent in developing countries like Nigeria. From the study data, keeping up with global trend (89\%) was suggested as a facilitator of m-commerce adoption. The ostentatious culture describes people doing or buying things that they may not necessarily understand or need, just to keep up with what is trending or fashionable. For instance, uptake of smart phones in Nigeria is on the increase (The Nation 2015); yet, the rate of m-commerce adoption is not commensurate with this level of smart phone uptake. This could be because users within the Nigerian context buy new or evolving technologies as a way of identifying with a social class. As one technology blogger in Nigeria noted, the high end prices and perception of iPhones as "status symbols" helps to drive the sale of this and similar brands in Nigeria (Arinze 2013). This suggests that the incline towards identifying 
with a social class or status can influence Nigerians' decisions with respect to technology adoption. Therefore, businesses can take advantage of this culture to engage more customers by, for example, engaging celebrities in their $\mathrm{m}$-commerce adoption campaign or approach.

MTN, a multinational mobile telecommunication company, is an example of a company that has leveraged this culture within her business model. In 2015, the company introduced a new service called MTN CallerFeel in Nigeria (MTN 2015, MTN Online). This service allows individuals and businesses to customise short messages that will appear on their callers' phone screen when they call (Daily Independent 2015). While this service has been adopted by businesses for advertisement purposes, there exist individuals who take up this service as a way of putting their status in the spotlight in order to impress their callers. In addition to the benefits that businesses can gain by advertising through this medium, MTN is also generating additional revenue through subscriptions on this innovative service. As at September 2018, HypeStat, a website analysis and statistics platform, estimates that MTN could generate up to $\$ 25,677.39$ (over 9 million Nigerian naira) yearly through the MTN CallerFeel website (HypeStat 2018). In addition, MTN reported that the introduction of various information services including the CallerFeel contributed to a $17.1 \%$ increase in revenue between 2014 and 2015 (MTN Nigeria 2016). These estimates suggest that this service has a viability within the Nigerian market, due to its alignment to the ostentatious culture. Therefore, businesses can also leverage this culture in their branding and/or product or service offering in order to generate additional income.

\section{Multi-SIM Culture}

Another socio-cultural factor that can influence m-commerce adoption in developing countries like Nigeria is the presence of a multi-SIM culture which cascades into a unique mobile phone culture. This culture developed as a consumer response to poor network, quality of service and a way to cash in on low service tariffs (Quartz 2015). As a result, it is estimated that the average Nigerian has at least 2-4 mobile numbers (GSMA 2014, Onyango-Obbo 2014). Although this culture can be viewed as a behavioural response to the nagging challenge of poor infrastructure in Nigeria, this behaviour has grown to become a culture as can be observed among many Nigerians in diaspora who naturally default to purchasing dual SIM phones or obtaining multiple phones or SIM cards despite not being confronted by similar challenges of poor infrastructure in those countries.

A report released by OpenSignal (2015) revealed that Nigeria had the highest proportion of users with multi SIM phones at $66 \%$. Although more recent statistics shows that Nigeria is now ranked fifth in terms of her use of multi SIM phones, the statistics still shows an increase in the use of multi SIM phones in Nigeria from the 66\% reported in 2015 to $75 \%$ in 2018 (Scientiamobile 2018). These figures reflect the high dependence on mobile phones in Nigeria. The data also buttresses the importance and benefit of this multi-SIM culture to micro and small businesses in Nigeria. The presence of this culture means that businesses are able to provide alternative phone numbers for their customers and suppliers to reach them; thereby 
helping to build valuable business relationships, while increasing customer trust in the business. The adoption of this culture by individuals also means that businesses are able to reach their customers for important business transactions e.g. confirmation of delivery. A practical example of this is the growing taxi hire service in Nigeria. While in most developed countries, it is often the case that a rider might not receive a call until when the driver arrives and is perhaps waiting for the rider, in developing countries like Nigeria, when a rider requests a taxi hire, it is often the case that the driver will call the rider to confirm the trip and also confirm the address. In cases where customers cannot be reached at such important times, perhaps due to ongoing limitations associated with the infrastructure, business opportunities could be lost.

The multi-SIM culture is further emphasised by the presence of affordable dual SIM phones. The study data showed that $81 \%$ of micro and small businesses indicated that affordability of device is one of the facilitators for their adoption of m-commerce. As smart mobile devices are becoming more affordable, individuals and businesses are becoming more reliant on this technology for communication and mobile access to internet based services; thereby increasing their adoption of $\mathrm{m}$-commerce. This increasing uptake of mobile devices due to affordability, and the increasing reliance on same, creates further opportunities for businesses to increase their customer touch points. It also opens the door for innovative uses of social media to interact and engage with new and existing customers; while observing patterns in consumer behaviour and gaining valuable feedback and/or reaction on their products or services.

\section{Conclusions}

Summarily, three socio-cultural factors that influence m-commerce adoption were discussed - personal relationship, ostentatious culture and multi-SIM culture. These factors are unique to, and prevalent in a developing economy like Nigeria. Combining responses garnered from participants and findings from literature, the discussion underscored the importance and contribution of these factors to the benefits that businesses can reap through the adoption of m-commerce. In addition, effective strategies to engage or address these factors were discussed. One such strategy highlighted the possibility of creating consumer trust through personal relationship. One way this can be achieved in the Nigerian context is by organizing physical campaigns to complement media advertisements, thereby positively influencing the perception, acceptance and patronage of a brand or company. Also, taking advantage of the ostentatious and multi-SIM culture can significantly contribute towards increasing the uptake of m-commerce, and the likelihood of more customers reaching the business. Overall, the responses from existing businesses show that engaging these socio-cultural factors can promote the adoption of $\mathrm{m}$-commerce. This can also provide additional benefits that businesses seeking to operate in cultures similar to the Nigerian context e.g., India, can focus on, to facilitate their adoption of $\mathrm{m}$-commerce, and to deliver noticeable benefits to their businesses. 


\section{Limitations}

The study research design, methodology, data collection and analysis were robustly and rigorously conducted in line with best practice. However, certain limitations are identified, which does not undermine or limit the results of the study, but is a recognition that different patterns may be observed should the research be conducted in a different context, such as across big businesses, or within developing countries under security threat or political tension. As such, care should be taken when the results of this study is applied to other cultural contexts that are different from Nigeria.

\section{References}

Al-Jabri IM, Sohail SM (2012) Mobile banking adoption: application of diffusion of innovation theory. Journal of Electronic Commerce Research 13(4): 379-392.

Arinze A (2013) Top ten mobile phone brands in Nigeria. Connect Nigeria. Retrieved from: http://connectnigeria.com/articles/2013/08/top-ten-mobile-phone-brands-innigeria/.

Ball D, Coelho PS, Machás A (2004) The role of communication and trust in explaining customer loyalty: an extension to the ECSI model. European Journal of Marketing 38(9/10): 1272-1293.

Benou P, Vassilakis C, Vrechopoulos A (2012) Context management for m-commerce applications: determinants, methodology and the role of marketing. Information Technology and Management 13(2): 91-111.

Bouwman H, Carlsson C, Molina-Castillo FJ, Walden P (2007) Barriers and drivers in the adoption of current and future mobile services in Finland. Telematics and Informatics 24(2): $145-160$.

Braun V, Clarke V (2006) Using thematic analysis in psychology. Qualitative Research in Psychology 3(2): 77-101.

Chiemeke SC, Evwiekpaefe AE (2011) A conceptual framework of a modified unified theory of acceptance and use of technology (UTAUT) model with Nigerian factors in e-commerce adoption. Educational Research 2(12): 1719-1726.

Chong AYL (2013) Predicting m-commerce adoption determinants: a neural network approach. Expert Systems with Applications 40(2): 523-530.

Cyr D, Head M, Ivanov A (2006) Design aesthetics leading to m-loyalty in mobile commerce. Information \& Management 43(8): 950-963.

Daily Independent (2015) MTN boosts subscribers experience with innovative service. Retrieved from: http://dailyindependentnig.com/2015/06/mtn-boosts-subscribersexperience-innovative-service/.

Datta P (2011) A preliminary study of ecommerce adoption in developing countries. Information Systems Journal 21(1): 3-32.

Efendioglu AM, Yip VF, Murray WL (2005) e-commerce in developing countries: issues and influences. In $4^{\text {th }}$ International Business and Economy Conference (IBEC 2005). Indian Institute of Mass Communication. Retrieved from: http://iimc.nic.in/publi cation-communicator.html.

GSMA (2014) Analysis - country overview: Nigeria. Retrieved from: http://draft-content. gsmaintelligence.com/AR/assets/4161587/GSMA_M4D_Impact_Country_Overview _Nigeria.pdf. 
Hajli MN, Lin X, Featherman M, Wang Y (2014) Social word of mouth: how trust develops in the market. International Journal of Market Research 56(5): 673-690.

Hung S, Ku C, Chang C (2003) Critical factors of WAP services adoption: an empirical study. Electronic Commerce Research and Applications 2(1): 42-60.

HypeStat (2018) CallerFeel.Mtnonline.Com - Info. Retrieved from: http://callerfeel.mt nonline.com.hypestat.com/.

ITU (2017) ICT facts and figures 2017. International Telecommunication Union. Retrieved from: https://bit.ly/2YgQgqM.

Khalifa M, Shen KN (2008) Explaining the adoption of transactional B2C mobile commerce. Journal of Enterprise Information Management 21(2): 110-124.

Kim S, Park H (2012) Effects of various characteristics of social commerce (s-commerce) on consumers' trust and trust performance. International Journal of Information Management 33(2): 318-332.

Lawrence JE, Tar UA (2010) Barriers to e-commerce in developing countries. Information, Society and Justice 3(1): 23-35.

Lee YE, Benbasat I (2003) Interface design for mobile commerce. Communications of the ACM 46(12): 48-52.

Lu J, Yao JE, Yu CS (2005) Personal innovativeness, social influences and adoption of wireless Internet services via mobile technology. The Journal of Strategic Information Systems 14(3): 245-268.

Luarn P, Lin HH (2005) Toward an understanding of the behavioral intention to use mobile banking. Computers in Human Behavior 21(6): 873-891.

Meuter ML, McCabe DB, Curran JM (2013) Electronic word-of-mouth versus interpersonal word-of-mouth: are all forms of word-of-mouth equally influential? Services Marketing Quarterly 34(3): 240-256.

Min Q, Li S, Zhong Q (2009) An empirical study of m-commerce adoption from usability perspective. In $20098^{\text {th }}$ International Conference on Mobile Business, 215-220. IEEE.

Molla A, Licker PS (2005) e-commerce adoption in developing countries: a model and instrument. Information \& Management 42(6): 877-899.

MTN (Online) MTN CallerFeel. Retrieved from: https://www.mtnonline.com/callerfeel.

MTN (2015) MTN CallerFeel. Retrieved from: https://bit.ly/35hI1fy.

MTN Nigeria (2016) MTN Nigeria investor day presentation. Retrieved from: https://bit. ly/2W6KfKU.

NCC (2018) Industry statistics. Subscriber/teledensity data. Retrieved from: https://www. ncc.gov.ng/stakeholder/statistics-reports/industry-overview\#view-graphs-tables.

Nysveen H, Pedersen PE, Thorbjørnsen H (2005) Intentions to use mobile services: antecedents and cross-service comparisons. Journal of the Academy of Marketing Science 33(3): 330-346.

Omonedo P, Bocij P (2014) e-commerce versus m-commerce: where is the dividing line? International Journal of Science, Education, Economics and Management Engineering 8(11): 3402-3407.

Omonedo P, Bocij P (2017) Potential impact of perceived security, trust, cost and social influence on m-commerce adoption in a developing economy. World Journal of Social Sciences 7(1): 147-160.

Onyango-Obbo C (2014) The good, the bad, the ugly: 15 things in which Nigeria leads or trails Africa. Retrieved from: http://mgafrica.com/article/2014-08-14-the-good-thebad-the-ugly-15-things-in-which-nigeria-leads-or-trails-africa-1.

OpenSignal (2015) 25\% of Android devices are dual-SIM, but not everywhere. The global prevalence of dual-SIM Android devices - January 2015. Retrieved from: https://ope nsignal.com/reports/2015/01/android-devices-dual-sim/. 
Quartz (2015) How Nigeria became the world's dual SIM-card superpower. Retrieved from: http://qz.com/345991/how-nigeria-became-the-worlds-dual-sim-card-superpo wer/.

Scientiamobile (2018) Top dual SIM phones and countries 2018. Retrieved from: https:// www.scientiamobile.com/top-dual-sim-phones-2018/.

Silverman D (2011) Qualitative research. $3^{\text {rd }}$ Edition. London: Sage Publications Ltd.

Song J (2010) Status quo and challenge of m-commerce in China. In 2010 Second International Conference on Communication Systems, Networks and Applications, 252-255. IEEE.

The Nation (2015) Smartphone penetration in Nigeria hits 30\%. Retrieved from: http:// thenationonlineng.net/smartphone-penetration-in-nigeria-hits-30/.

Verkasalo H, López-Nicolás C, Molina-Castillo FJ, Bouwman H (2010) Analysis of users and non-users of smartphone applications. Telematics and Informatics 27(3): 242255.

WeAreSocial (2019) Digital around the world in 2019. Retrieved from: https://wearesoci al.com/blog/2019/01/digital-2019-global-internet-use-accelerates.

Wei TT, Marthandan G, Chong AYL, Ooi KB, Arumugam S (2009) What drives Malaysian m-commerce adoption? An empirical analysis. Industrial Management \& Data Systems 109(3): 370-388.

Wu JH, Wang SC (2005) What drives mobile commerce? Information \& Management 42(5): 719-729.

Xin C (2009) m-commerce development and challenges facing. In 2009 IITA International Conference on Services Science, Management and Engineering, 229-232. IEEE.

Xu H, Gupta S (2009) The effects of privacy concerns and personal innovativeness on potential and experienced customers' adoption of location-based services. Electronic Markets 19(2-3): 137-149.

Zhang JJ, Yuan Y, Archer N (2002) Driving forces for m-commerce success. Journal of Internet Commerce 1(3): 81-106.

Zhang L, Zhu J, Liu Q (2012) A meta-analysis of mobile commerce adoption and the moderating effect of culture. Computers in Human Behavior 28(5): 1902-1911. 